Available online at Journal Website
https://ijma.journals.ekb.eg/
Main subject [Medicine [Obstetrics, Psychiatry]]

Original article

\title{
Alteration of Sexual Function among Females after Laparoscopic and Abdominal Hysterectomy
}

\author{
Ahmed Adel Mahmouda; Walaa Mohammed El-Bassioune ${ }^{\mathbf{b}}$; Ayman Alhosseiny Abdelmaksoud $\mathbf{c}$; Ahmed \\ Mohamed Abd-Eltawab ${ }^{\mathbf{b}}$
}

Department of Obstetrics and Gynecology, Dikirnis General Hospital, Ministry of Health, Egypt ${ }^{[a]}$.

Department of Obstetrics and Gynecology, Damietta Faculty of Medicine, Al-Azhar University, Egypt ${ }^{[\mathrm{b}] \text {. }}$

Department of Psychiatry, Damietta Faculty of Medicine, Al-Azhar University, Egypt $[\mathbf{c}]$.

Corresponding author: Ahmed Adel Mahmoud

Email: a.adle@domazhermedicine.edu.eg

Submitted at: February 19, 2020; Revised at: March 26, 2020; Accepted at: March 27, 2020; Available online at: March 27, 2020

DOI: 10.21608/ijma.2020.24351.1102

\begin{abstract}
Background: Alteration of the female sexual functions after hysterectomy have a great concern to patients and clinicians. The introduction of many assessment tools as the Female Sexual Function Index (FSFI) allowed researchers to assess the sexual functions in a more standardized method.
\end{abstract}

Aim of the work: To assess the consequence of abdominal and laparoscopic hysterectomy on sexual functions.

Patients and Methods: 60 women aged between 30 to 60 years who underwent hysterectomy (abdominal or laparoscopic) for benign reasons were included in this study, and divided into two groups, total abdominal hysterectomy (TAH) and total laparoscopic hysterectomy (TLH). Using FSFI questionnaire, the sexual functions were assessed 1 day preoperatively and six months postoperatively.

Results: The score for Desire was $5.08+0.62$ for TAH, $5.06+0.60$ for TLH preoperatively; and $5.12+0.58$ for TAH, $5.20+0.62$ for TLH postoperatively. Arousal was $5.14+0.42$ for TAH, $5.19+0.42$ for TLH preoperatively and $5.15+0.53$ for TAH, $5.22+0.46$ for TLH postoperatively. Lubrication was $5.05+0.49$ for TAH, $5.15+0.52$ for TLH preoperatively and $5.23+0.48$ for TAH, $5.23+0.53$ for TLH postoperatively. Orgasm was $5.01+0.62$ for TAH, $5.00+0.57$ for TLH preoperatively and $5.04+0.59$ for TAH, $5.13+0.59$ for TLH postoperatively. Satisfaction was $4.89+0.63$ for TAH \&4.89+0.60 for TLH preoperatively and $5.00+0.66$ for TAH, $5.20+0.60$ for TLH postoperatively. Pain was $4.95+0.48$ for TAH, $4.95+0.51$ for TLH preoperatively and $5.12+0.53$ for TAH, $5.01+0.51$ for TLH postoperatively.

Conclusion: There was a significant improvement in the female sexual functions after laparoscopic hysterectomy, but after abdominal hysterectomy, there was no improvement.

Keywords: Female Sexual Function Index; Arousal; Lubrication, Orgasm; Hysterectomy.

This is an open access article under the Creative Commons license [CC BY] [https://creativecommons.org/licenses/by/2.0/]

Please cite this article as: Mahmoud AA, El-Bassioune WM, Abdelmaksoud AA, Abd-Eltawab AM. Alteration of Sexual Function among Females after Laparoscopic and Abdominal Hysterectomy. IJMA 2020; 2[2]: 442-450.

* Main subject and any subcategories have been classified according to researchers' main field of study. 


\section{INTRODUCTION}

Hysterectomy is the most commonly performed operation in the gynecological practice [1]. About $40 \%$ of women undergo Hysterectomy before reaching the age of 64 . However, $90 \%$ of these surgeries are due to benign reasons [2], in order to raise life quality. However, it can bring some postoperative long-term problems such as depression, sexual dysfunction and especially, urinary incontinence [3].

To date, many studies have confirmed the advantage of the laparoscopic hysterectomy as a safe method with good postoperative recovery, a shorter hospital stay and reduced need for analgesics [4].

Most of the women who proceed hysterectomy are worried about how it will affect their sexuality, and, regrettably, there is still no consensus about the effects of the surgery on female sexuality ${ }^{[5]}$.

In addition, it is assumed that the removal of the uterus basically affects the anatomical structures of the pelvis, including the nerve supply of the pelvis [6]. On the sexual side, neural supply in the upper part of the vagina is thought to interfere with orgasm and lubrication ${ }^{[7]}$.

It has been supposed that a significant minority of females who undergone hysterectomy had a decrease in their sexual function [5]. On the other hand, some studies reported improvement in female sexual function after hysterectomy ${ }^{[8]}$.

Moreover, some studies found that alleviation of sexuality problems and anxieties of partners underwent hysterectomy has a positive effect quality of life of the patients $[9,10]$.

Therefore, there is an outstanding debate regarding the benefits and drawbacks of the various types of hysterectomy. Therefore, in this study we tried to investigate the impact of different types of hysterectomy on the female sexual functions.

\section{AIM OF THE STUDY}

The aim of this study was to evaluate the effect of abdominal and laparoscopic hysterectomy on sexual functions.

\section{PATIENT AND METHODS}

Sixty women aged between 30 to 60 years old participated in this study, where they were divided equally into two groups. The first one had abdominal hysterectomy while second group had laparoscopic hysterectomy. The study was conducted in Obstetrics and Gynecology Department of Al-Azhar University (Damietta) from May 2019 till January 2020.

Study Design: Analytical prospective study.

\section{Inclusion criteria}

Patients who were sexually active and performed hysterectomy for benign causes, patients aged between (30-60) years, patients who underwent hysterectomy (from June 2019 to January 2020), patients that free from medical problems such as DM or hypertension and patients in which hysterectomy without concurrent unilateral or bilateral adnexectomy was done for a benign gynecological disease were included .

\section{Exclusion criteria}

Patients who were under severe depression before the operation, patients who had been using antidepressant medications, patients who had sexual dysfunction, patients who had complications during the operation or in the period after operation, patients whose partners had a severe illness or had died in the meantime, patients who did not want to continue, patients who were suspected of malignancy and the need for concurrent interventions such as prolapse repair were excluded.

\section{Methodology}

Before operation, all patients undergone transvaginal ultrasounds, gynecological examination, routine laboratory tests were performed and medical histories were obtained. Patients were categorized into two groups according to the type of surgical operation: the total abdominal hysterectomy group (TAH) and the total laparoscopic hysterectomy group (TLH).

\section{Data collection}

A written consent for participation in the study was obtained from each woman. Also, each woman was interviewed for an about of half an hour verbal interview for assisting the sexual function and quality of life were. This done on two sets, assessed 1 day preoperatively on admission to the hospital \& after 6 months postoperatively. The questionnaire included Female data as age (years), parity, educational level, 
menopausal status at time of surgery (pre, peri or postmenopausal), type of surgical procedure (abdominal or laparoscopic), in addition to the data for assessing the sexual function.

\section{Female Sexual Function Index (FSFI) [11]}

For the evaluation of their sexual functions, FSFI scales were used through face-to-face meeting held 1 day preoperatively on admission to the hospital and six months after the operation.

This index consists of 19 questions grouped in six domains or dimensions:

0 Desire (items 1 and 2);

o Arousal (items 3 - 6);

o Lubrication (items 7 - 10);

o Orgasm (items 11 - 13);

0 Satisfaction (items 14 - 16) and

o Pain (items 17 - 19).

Cases having a total FSFI score of $\leq 26.55$ were defined as having sexual dysfunction. All questionnaires were coded with an identifying number, and women could not view their previous answers.

\section{Operating procedures}

All patients received preoperative prophylactic antibiotics as well as anticoagulants during immobilization. All Hysterectomies either TLH or TAH were performed using the standard extra-fascial technique by means of clamps and suture ligation. The technical aspects of both types of hysterectomy were discussed with each patient, and the appropriate hysterectomy type was selected through mutual discussion.

Statistical analysis: Data were analyzed using Statistical Program for Social Science (SPSS) version 24. Quantitative data were expressed as mean \pm standard deviation (SD). Qualitative data were expressed as frequency and percentage. Ttests were used to compare between two means. Pvalue $<0.05$ was considered significant.

\section{RESULTS}

A total number of 60 patients aged between 30 to 60 years old. 30 patients had abdominal hysterectomy $(\mathrm{TAH})$ with mean age $44.53 \pm 5.59$ years and 30 patients had laparoscopic hysterectomy (TLH) with mean age $44.37 \pm 6.72$ years. When comparing the mean age between groups there were no statistically significant difference ( $P$ - value $=0.92)$. The mean body mass index for the TLH group were $33.20 \pm 7.51 \mathrm{~kg} / \mathrm{m}^{2}$ and $31.78 \pm 7.99 \mathrm{~kg} / \mathrm{m}^{2}$ for the TAH group. When comparing the means between groups there were no statistically significant difference ( $P$-value $=0.48)$. The mean Partner age for the TLH group were 50.83 \pm 8.63 years and $51.90 \pm 8.74$ years for the $\mathrm{TAH}$ group. When comparing the means between groups there were no statistically significant difference ( $P$ value $=0.64)$ (Table 1).

Regarding the Indication for hysterectomy 25 women $(41.7 \%)$ had uterine leiomyomas, $21(35.0 \%)$ had abnormal uterine bleeding, 8 (13.3\%) had Adenomyosis \& $6(10.0 \%)$ had cervical pathology. More than two-third of women were Premenopausal. Disruptive data of Education, Occupation, Residence, Parity \& Route of delivery of the studied population were presented in table [2].

The Female Sexual Function Index (FSFI) Questionnaire in the TLH group, the Desire questions taken 1 day before operation in the TLH group have a mean of $5.06 \pm 0.60$ score and the questions taken 6 months after operation have a mean of $5.20 \pm 0.62$. When comparing the means between groups there were no statistically significant difference ( $P$-value $=0.26)$.

Regarding the Arousal questions, the average score for 1 day before operation was $5.14 \pm 0.42$ \& $5.19 \pm 0.42$ for TAH \& TLH respectively. Six months after operation the score was $5.15 \pm 0.53 \& 5.22 \pm$ 0.46 for TAH \& TLH respectively. No statistically significant difference was observed between pre \& post-operative score regarding each group (Table 3 , 4). When asking about the Lubrication, the average score for 1 day before operation was $5.05 \pm 0.49$ \& $5.15 \pm 0.52$ for TAH \& TLH respectively. Six months after operation the score was $5.23 \pm 0.48 \& 5.23 \pm$ 0.53 for TAH \& TLH respectively. There was only a statistically significant increase in the TAH group ( $P$ value $=0.01$ ) (Tables 3 and 4).

The Orgasm questions taken 1 day before operation in the TAH group have a mean of $5.01 \pm$ 0.62 score and the questions taken 6 months after operation have a mean of $5.04 \pm 0.59$. When comparing the means between groups there were no statistically significant difference $(P$-value $=0.83)$. On 
the other hand, the score taken 1 day before operation in the TLH group have a mean of $5 \pm 0.57$ and the questions taken 6 months after operation have a mean of $5.13 \pm 0.59$. When comparing the means between groups there were no statistically significant difference (P-value $=0.26)$. Women's sexual Satisfaction increased significantly ( $P$ value $=0.04$ ) in the TLH group from score of $4.89 \pm$ 0.6 to $5.2 \pm 0.6$ post- operatively. However, in the TAH group despite that there was an increase in the score from $4.89 \pm 0.63$ to $5 \pm 0.66$, the increased score was not no statistically significant ( $P$ value $=0.23$ ) (Tables 3 and 4).

Pain occurs within intercourse had reported \& recorded a score of $4.95 \pm 0.48$ in the day before operation in the TAH group \& the score increased to $5.12 \pm 0.53$ post-operatively with no statistically significant difference $(P$-value $=0.09)$. On the other hand, Pain recorded in TLH group have a mean of $4.95 \pm 0.51$ score in the day before operation that increased also to $5.01 \pm 0.51$ post-operatively no statistically significant difference $(P$-value $=0.57)$ (Tables 3 and 4).

The total score of questions taken 1 day before operation in the TAH group have a mean of $30.12 \pm$ 2 score and the questions taken 6 months after operation have a mean of $30.66 \pm 2.32$. When comparing the means between groups there were no statistically significant difference $(P$ - value $=0.12$ ). While the total score of questions taken 1 day before operation in the TLH group have a mean of $30.24 \pm$ 1.92 score and the questions taken 6 months after operation have a mean of $31 \pm 2.49$. When comparing the means between groups there were a statistically significant difference $(P$-value $=0.02)$ with the mean score after 6 months being higher than 1 day before.

Correlation between patient's data in the TLH group and TAH group showed that there is no statistical significance between the groups (Education: $P$-value $=0.93$, Occupation: $P$-value= 0.59 , Residence: P-value $=0.80$, Route of delivery: $P$-value $=0.79$, Menopausal status: $P$-value $=0.78$, Parity: $P$-value $=0.86$ and Indication for hysterectomy: P-value= 0.05).

The Female Sexual Function Index (FSFI) Questionnaire in the TAH group revealed that, the Desire questions taken 1 day before operation in the TAH group have a mean of $5.08 \pm 0.62$ score and the questions taken 6 months after operation have a mean of $5.12 \pm 0.58$. When comparing the means between groups there were no statistically significant difference (P-value $=0.72)$.

Regarding the Arousal questions taken 1 day before operation in the TAH group have a mean of $5.14 \pm 0.42$ score and the questions taken 6 months after operation have a mean of $5.15 \pm 0.53$. When comparing the means between groups there were no statistically significant difference $(P-$ value $=0.91)$.

The Lubrication questions taken 1 day before operation in the TAH group have a mean of $5.05 \pm$ 0.49 score and the questions taken 6 months after operation have a mean of $5.23 \pm 0.48$. When comparing the means between groups there were a statistically significant difference $(P$-value $=0.01)$ with the mean score after 6 months being higher than 1day before. The Orgasm questions taken 1 day before operation in the TAH group have a mean of $5.01 \pm 0.62$ score and the questions taken 6 months after operation have a mean of $5.04 \pm 0.59$. When comparing the means between groups there were no statistically significant difference (P-value=0.83).

The Satisfaction questions taken 1 day before operation in the TAH group have a mean of $4.89 \pm$ 0.63 score and the questions taken 6 months after operation have a mean of $5 \pm 0.66$. When comparing the means between groups there were no statistically significant difference ( $P$ - value $=0.23$ ). The Pain questions taken 1 day before operation in the TAH group have a mean of $4.95 \pm 0.48$ score and the questions taken 6 months after operation have a mean of $5.12 \pm 0.53$. When comparing the means between groups there were no statistically significant difference $(P$-value $=0.09)$. The total score of questions taken 1 day before operation in the TAH group have a mean of $30.12 \pm 2$ score and the questions taken 6 months after operation have a mean of $30.66 \pm 2.32$. When comparing the means between groups there were no statistically significant difference ( $P$ - value $=0.12$ ).

Correlation between patient's data in the TLH group and TAH group showed that there is no statistical significance between the groups (Education: $P$-value $=0.93$, Occupation: $P$-value $=$ 0.59 , Residence: $P$-value $=0.80$, Route of delivery: $P$-value $=0.79$, Menopausal status: $P$-value $=0.78$, Parity: $P$-value $=0.86$ and Indication for hysterectomy: P-value= 0.05). 
Mahmoud AA, et al.

Table [1]: Numeric demographic data of patients included in the study groups and comparing the means of each group $(n=30)$.

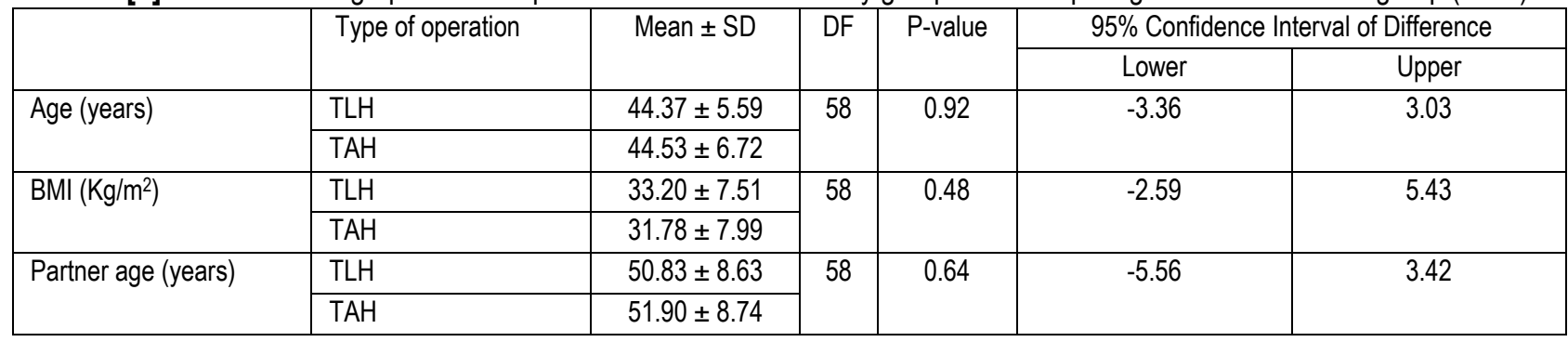

Table [2]: Descriptive statistics of patient's data included in the study.

\begin{tabular}{|c|c|c|}
\hline \multirow{6}{*}{ Education } & & $n(\%)$ \\
\hline & Primary & $14(23.3 \%)$ \\
\hline & Secondary & $15(25.0 \%)$ \\
\hline & High & $14(23.3 \%)$ \\
\hline & None & $5(8.3 \%)$ \\
\hline & University & $12(20.0 \%)$ \\
\hline \multirow[t]{2}{*}{ Occupation } & House wife & $38(63.3 \%)$ \\
\hline & Work & $22(36.7 \%)$ \\
\hline \multirow[t]{2}{*}{ Residence } & Rural & $33(55.0 \%)$ \\
\hline & Urban & $27(45.0 \%)$ \\
\hline \multirow[t]{3}{*}{ Menopausal status } & Peri-menopausal & $10(16.7 \%)$ \\
\hline & Post-menopausal & $10(16.7 \%)$ \\
\hline & Pre-menopausal & $40(66.7 \%)$ \\
\hline \multirow[t]{7}{*}{ Parity } & $\mathrm{PO}$ & $9(15.0 \%)$ \\
\hline & P1 & $8(13.3 \%)$ \\
\hline & $P 2$ & $16(26.7 \%)$ \\
\hline & P3 & $12(20.0 \%)$ \\
\hline & P4 & $11(18.3 \%)$ \\
\hline & P5 & $3(5.0 \%)$ \\
\hline & $P 6$ & $1(1.7 \%)$ \\
\hline \multirow[t]{2}{*}{ Route of delivery } & C.S. & $23(38.3 \%)$ \\
\hline & Vaginal & $37(61.7 \%)$ \\
\hline \multirow[t]{4}{*}{ Indication for hysterectomy } & Uterine leiomyomas & $25(41.7 \%)$ \\
\hline & Abnormal uterine bleeding & $21(35.0 \%)$ \\
\hline & Adenomyosis & $8(13.3 \%)$ \\
\hline & Cervical pathology & $6(10.0 \%)$ \\
\hline \multirow[t]{2}{*}{ Type of operation } & TLH & $30(50.0 \%)$ \\
\hline & TAH & $30(50.0 \%)$ \\
\hline
\end{tabular}

Table (3): Comparing means of Questionnaire scores in the TLH group before and after operation $(n=30)$.

\begin{tabular}{|c|c|c|c|c|c|c|c|}
\hline & \multirow{2}{*}{ Time of Questionnaire } & \multirow[t]{2}{*}{ Mean } & \multirow[t]{2}{*}{ SD } & \multirow[t]{2}{*}{ DF } & \multirow[t]{2}{*}{ P-value } & \multicolumn{2}{|c|}{$95 \%$ Confidence Interval of the Difference } \\
\hline & & & & & & Lower & Upper \\
\hline \multirow[t]{2}{*}{ Desire } & One day Before & 5.06 & 0.60 & \multirow[t]{2}{*}{29} & \multirow[t]{2}{*}{0.26} & \multirow[t]{2}{*}{-0.39} & \multirow[t]{2}{*}{0.11} \\
\hline & Six months After & 5.20 & 0.62 & & & & \\
\hline \multirow[t]{2}{*}{ Arousal } & One day Before & 5.19 & 0.42 & \multirow[t]{2}{*}{29} & \multirow[t]{2}{*}{0.77} & \multirow[t]{2}{*}{-0.23} & \multirow[t]{2}{*}{0.17} \\
\hline & Six months After & 5.22 & 0.46 & & & & \\
\hline \multirow[t]{2}{*}{ Lubrication } & One day Before & 5.15 & 0.52 & \multirow[t]{2}{*}{29} & \multirow[t]{2}{*}{0.50} & \multirow[t]{2}{*}{-0.32} & \multirow[t]{2}{*}{0.16} \\
\hline & Six months After & 5.23 & 0.53 & & & & \\
\hline \multirow[t]{2}{*}{ Orgasm } & One day Before & 5.00 & 0.57 & \multirow[t]{2}{*}{29} & \multirow[t]{2}{*}{0.26} & \multirow[t]{2}{*}{-0.37} & \multirow[t]{2}{*}{0.10} \\
\hline & Six months After & 5.13 & 0.59 & & & & \\
\hline \multirow[t]{2}{*}{ Satisfaction } & One day Before & 4.89 & 0.60 & \multirow[t]{2}{*}{29} & \multirow[t]{2}{*}{0.04} & \multirow[t]{2}{*}{-0.59} & \multirow[t]{2}{*}{-0.02} \\
\hline & Six months After & 5.20 & 0.60 & & & & \\
\hline \multirow{2}{*}{ Pain } & One day Before & 4.95 & 0.51 & \multirow[t]{2}{*}{29} & \multirow{2}{*}{0.57} & \multirow[t]{2}{*}{-0.30} & \multirow[t]{2}{*}{0.17} \\
\hline & Six months After & 5.01 & 0.51 & & & & \\
\hline \multirow[t]{2}{*}{ Total score } & One day Before & 30.24 & 1.92 & 29 & 0.02 & -1.39 & -0.12 \\
\hline & Six months After & 31.00 & 2.49 & & & & \\
\hline
\end{tabular}


Table (4): Comparing means of Questionnaire scores in the TAH group before and after operation $(n=30)$.

\begin{tabular}{|c|c|c|c|c|c|c|c|}
\hline & \multirow[t]{2}{*}{ Time of Questionnaire } & \multirow[t]{2}{*}{ Mean } & \multirow[t]{2}{*}{ SD } & \multirow[t]{2}{*}{ DF } & \multirow[t]{2}{*}{ P-value } & \multicolumn{2}{|c|}{$95 \%$ Confidence Interval of the Difference } \\
\hline & & & & & & Lower & Upper \\
\hline \multirow[t]{2}{*}{ Desire } & One day Before & 5.08 & 0.62 & \multirow[t]{2}{*}{29} & \multirow[t]{2}{*}{0.72} & \multirow[t]{2}{*}{-0.27} & \multirow[t]{2}{*}{0.19} \\
\hline & Six months After & 5.12 & 0.58 & & & & \\
\hline \multirow[t]{2}{*}{ Arousal } & One day Before & 5.14 & 0.42 & \multirow[t]{2}{*}{29} & \multirow[t]{2}{*}{0.91} & \multirow[t]{2}{*}{-0.18} & \multirow[t]{2}{*}{0.16} \\
\hline & Six months After & 5.15 & 0.53 & & & & \\
\hline \multirow[t]{2}{*}{ Lubrication } & One day Before & 5.05 & 0.49 & \multirow[t]{2}{*}{29} & \multirow[t]{2}{*}{$0.01^{*}$} & \multirow[t]{2}{*}{-0.32} & \multirow[t]{2}{*}{-0.04} \\
\hline & Six months After & 5.23 & 0.48 & & & & \\
\hline \multirow[t]{2}{*}{ Orgasm } & One day Before & 5.01 & 0.62 & \multirow[t]{2}{*}{29} & \multirow[t]{2}{*}{0.83} & \multirow[t]{2}{*}{-0.27} & \multirow[t]{2}{*}{0.22} \\
\hline & Six months After & 5.04 & 0.59 & & & & \\
\hline \multirow[t]{2}{*}{ Satisfaction } & One day Before & 4.89 & 0.63 & \multirow[t]{2}{*}{29} & \multirow[t]{2}{*}{0.23} & \multirow[t]{2}{*}{-0.29} & \multirow[t]{2}{*}{0.07} \\
\hline & Six months After & 5.00 & 0.66 & & & & \\
\hline \multirow[t]{2}{*}{ Pain } & One day Before & 4.95 & 0.48 & \multirow[t]{2}{*}{29} & \multirow[t]{2}{*}{0.09} & \multirow[t]{2}{*}{-0.38} & \multirow[t]{2}{*}{0.03} \\
\hline & Six months After & 5.12 & 0.53 & & & & \\
\hline Total score & One day Before & 30.12 & 2.00 & 29 & 0.12 & -1.22 & 0.14 \\
\hline & Six months After & 30.66 & 2.32 & & & & \\
\hline
\end{tabular}

*: Statistically significant $(P<0.05$

\section{DISUCSSION}

Female sexual dysfunction affects all kinds of races, socioeconomic backgrounds and the entire spectrum of ages. Since various conditions and personal experiences adversely affect sexual health, it is not surprising that the prevalence of female sexual dysfunction (FSD) is high, ranging from 30 to $50 \%$ [12]. In the last years, the impact of hysterectomy on female sexual function have become a significant research topic. The introduction of validated assessment tools such as the Female Sexual Function Index (FSFI) made it easier to researchers to evaluate sexual function in a more standardized manner [13].

Regarding the age in this study, it is comparable to other studies that focused on the effect of hysterectomy on the female sexual function. Kim et al. [14], made a study on the total hysterectomy on the sexual function and the mean age (years) was $43.1 \pm 2.12$ slandered deviation in the total hysterectomy group. In addition, the mean age in years were $51.3 \pm 9.0$ and $47.3 \pm 5.9$ in the Laparoscopic approach and vaginal route of hysterectomy operation respectively [13]. In the same line, Eken et al. [15], discovered that the mean age in years were $42.8 \pm 2.5$ and $41.1 \pm 5.5$ in the total abdominal hysterectomy (TAH) and total laparascopic hysterectomy (TLH) groups respectively.

In the current study, the partner age was added, as a variable and the mean partner age is comparable to another study where the mean partner age (year) were $46.8 \pm 3.6$ and $48.6 \pm 6.3$ TAH and TLH groups respectively [15].

Regarding the mean body mass index for the TLH group, it was $33.20 \pm 7.51 \mathrm{~kg} / \mathrm{m}^{2}$ and $31.78 \pm$ $7.99 \mathrm{~kg} / \mathrm{m} 2$ for the TAH group. When comparing the means between groups there were no statistically significant difference (P-value $=0.48)$. Unlike the above results, the BMI was relatively lower in other studies focusing on hysterectomy and female sexual function. Nam et al. [16], reported a BMl of $22.8 \pm 3.16$ and $22.5 \pm 2.39 \mathrm{~kg} / \mathrm{m}^{2}$ in their study groups. In addition, Radosa et al. [17], found that the mean BMI were $26.93 \pm 6.57$ and $28.17 \pm 7.16$ and $26.14 \pm$ $5.92 \mathrm{~kg} / \mathrm{m}^{2}$ in their study groups. Also, Eken et al. [15], found that the mean BMI were $28.6 \pm 4.0$ and $29.5 \pm$ $6.9 \mathrm{~kg} / \mathrm{m}^{2}$ in the total abdominal hysterectomy (TAH) and total laparoscopic hysterectomy (TLH) groups respectively. This difference may be due to the cultural and dietary habits in Egypt and Middle East region. Farrell and Kieser ${ }^{[18]}$ conducted a systematic review of sexuality after hysterectomy and concluded that research in this field was mostly retrospective without the use of validated outcome measures.

Most of the studies found either no change or improvement of sexuality after hysterectomy. Theoretically hysterectomy should increase sexual pleasure by eliminating the fear of pregnancy, relieving dyspareunia and uterine disease especially malignant diseases [19].

Regarding the FSFI in the desire and arousal questions, in consistent with the present study differences in libido and sexual sensitivity following 
different types of hysterectomies have been evaluated by Wierrani et al.[20], and showed no difference at 12 months after operation. In the same line, Galyer et al.[21], compared sexual function in women who had underwent TAH with those who underwent $\mathrm{VH}$. There was no difference in sexual desire postoperatively between the groups. In addition, Roovers et al.[8] conducted a prospective study over 6 months and found a decrease in sexual problems with vaginal hysterectomy, TAH or sub$\mathrm{TAH}$. On the other hand, a prospective study done on a large scale (the Maryland Women's Health study) which included 1299 women who were interviewed with validated questionnaire preoperatively and at 6,12,18 and 24 months after hysterectomy for benign diseases and noticed a significant increase in frequency of sexual activity, a reduction in dyspareunia and a decrease in low libido[22],

A prospective study showed that there were no change of the sexual function in premenopausal women underwent either conventional or single port laparoscopic vaginal hysterectomy [23].

Regarding the FSFI in the lubrication and orgasm there were no difference before or after operation in both groups. The satisfaction questions showed improvement after operation in the TLH group but not in the TAH group. Dyspareunia following hysterectomy may be due to vaginal dryness. It may be present before hysterectomy. Vaginal dryness is usually not worsened in most of patients and is usually improved, particularly in women using hormone replacement therapy (HRT) following bilateral oophorectomy ${ }^{24]}$.

Vaginal dryness before hysterectomy is highly predictive of post-hysterectomy vaginal dryness. Vaginal dryness developed after hysterectomy is uncommon but may be associated with premature ovarian failure leading to decrease in endogenous estrogen production, or with inadequate hormone replacement [25]. It has been hypothesized that the interruption of innervation of upper vagina and cervix after total hysterectomy interferes with orgasm and lubrication [19].

The effect of anatomical changes was highlighted by comparing coital frequency, dyspareunia, libido and frequency of orgasm before and at 6 weeks, 6 months and 1 year in 105 women with $\mathrm{TAH}$ and 107 with sub TAH. The two groups showed an equal but mild reduction in dyspareunia and coital frequency with statistically significant deterioration after sub TAH. The frequency of orgasm was significantly reduced in TAH group but not in sub TAH group [26, 27]. However, two randomly designed studies ${ }^{[28,29]}$ showed no change in orgasm or frequency of intercourse between TAH and sub TAH. In addition, Thakar et al. [30], conducted a study on 279 women (146 TAH and 133 sub TAH and all women were followed for 1 year) showed that no statistical difference was noticed between the two groups before and after surgery. The desire for intercourse, frequency of intercourse, orgasm, and initiation of intercourse did not differ significantly among the groups.

The results in the current study showed a slight increase in the pain score, which means slight decrease in the pain during intercourse. This may be explained by that hysterectomy results in decrease in dyspareunia, with significant increase in the frequency of intercourse, which is considered as improvement of sexual function and enjoyment. The presence of symptoms before hysterectomy, adversely affect frequency of sexual relations in most cases and severely disturb relations. Elimination of these symptoms leads to improvement in sexual frequency, reflecting improvement in sexual functioning and enjoyment [25]. Chronic dyspareunia causes frequent painful sexual relations and therefor to avoidance. Therefore, the condition has a negative effect on emotional intimacy directly and indirectly by straining personal relationships. The probability of an unchanged or worsening the sexual function is greater for cases with depression and pain and for those who are less satisfied with the surgery they have had [31].

On the other hand, it has been assumed that hysterectomy could result in dyspareunia by decreasing the length of the vaginal vault, or even by causing vaginal fibrosis. Hysterectomy can also result in pain and dyspareunia due to the residual ovary syndrome and bowel adhesions [25].

Conclusion: The results of this study showed that there was a significant improvement in the female sexual functions after total laparoscopic hysterectomy, but after total abdominal hysterectomy, there was no improvement.

The strength of this study is that this type of research is not common in our society, hoping that it 
will have a good impact and encouraging the research in this field.

Limitations of this study are: The small number of cases that meet the inclusion criteria. Some women may choose not to contribute in the study because of the cultural factors present in our Middle Eastern community. The short-term follow-up after operation (six months) because long-term follow up may fail due to lake of interest of the cases.

\section{Financial and Non-Financial Relationships and Activities of Interest}

None

\section{REFERENCES}

1. Committee on Gynecologic Practice. Committee Opinion No 701: Choosing the Route of Hysterectomy for Benign Disease. Obstet Gynecol. 2017; 129 (6): e155e159. [DOI: 10.1097/AOG. 0000000000002112].

2. Doğanay M, Kokanali D, Kokanali MK, Cavkaytar S, Aksakal OS. (2019). Comparison of female sexual function in women who underwent abdominal or vaginal hysterectomy with or without bilateral salpingooophorectomy. J Gynecol Obstetr Human Reprod.2019; 48 (1): 29-32. [DOI: 10.1016/j.jogoh.2018.11.004].

3. Zahra M, Zahara F, Javed S, Atiq M, Hussain A. Outcomes of total hysterectomy. World J Pharmaceut Res. 2018; 7(11): 1524-1535. [DOI: 10.20959/wjpr2018 11-12740].

4. Hoffman CP, Kennedy J, Borschel L, Burchette R, Kidd A. Laparoscopic hysterectomy: the Kaiser Permanente San Diego experience. J Minim Invasive Gynecol. 2005; 12(1), 16-24. [DOI: 10.1016/j.jmig. 2004. 12.022].

5. Thakar R. Is the uterus a sexual organ? Sexual function following hysterectomy. Sex Med Reviews 2015; 3(4): 264-278. [DOI: 10.1002/smri.59].

6. Katz A. Sexuality after hysterectomy: A review of the literature and discussion of nurses' role. J Adv Nursing 2003; 42(3), 297-303. [DOI: 10.1046/j.1365-2648.2003. 02619.x].

7. Fram KM, Saleh SS, Sumrein IA. Sexuality after hysterectomy at University of Jordan Hospital: A teaching hospital experience. Arch Gynecol Obstetr. 2013; 287(4): 703-708. [DOI: 10.1136/bmj.327.7418.774].

8. Roovers JPW, van der Bom JG, van der Vaart CH, Heintz APM. Hysterectomy and sexual wellbeing: Prospective observational study of vaginal hysterectomy, subtotal abdominal hysterectomy, and total abdominal hysterectomy. BMJ 2003; 327(7418): 774-778. [DOI: 10.1136/bmj.327.7418.774].
9. Flory N, Bissonnette F, Binik YM. Psychosocial effects of hysterectomy: literature review. J Psychosom Res. 2005; 59(3), 117-129. [DOI: 10.1016/j.jpsychores. 2005.05.009].

10. Katz A. Sexuality and hysterectomy: Finding the right words: Responding to patients' concerns about the potential effects of surgery. AJN 2005; 105(12): 65-68. [DOI: 10.1097/00000446-200512000-00035].

11. Rosen C, Brown J, Heiman S, Leiblum C, Meston R, Shabsigh D, Ferguson R, D'Agostino R. (2000). The Female Sexual Function Index (FSFI): a multidimensional self-report instrument for the assessment of female sexual function. J Sex Marital Ther. 2000; 26(2): 191-208. [DOI: 10.1080/009262300278597].

12. Srivastava $R$, Thakar $R$, Sultan $A$. Female sexual dysfunction in obstetrics and gynecology. Obstetr Gynecol Survey 2008; 63(8), 527-537. [DOI: 10.1097/ogx.0b013e 31817f13e3].

13. Bastu E, Yasa C, Dural O, Ozgor BY, Yilmaz G, Ugurlucan FG, Banerjee S. Comparison of 2 methods of vaginal cuff closure at laparoscopic hysterectomy and their effect on female sexual function and vaginal length: A randomized clinical study. J Minim Inv Gynecol. 2016; 23(6), 986-993. [DOI: 10.1016/j.jmig.2016.07.007].

14. Kim DH, Lee YS, Lee ES. (2003). Alteration of sexual function after classic intrafascial supracervical hysterectomy and total hysterectomy. J Am Assoc Gynecol Laparosc. 2003; 10(1): 60-64. [DOI: 10.1016/s1074-3804 (05)60236-8].

15. Eken MK, İlhan G, Temizkan O, Çelik EE, Herkiloğlu D, Karateke A. The impact of abdominal and laparoscopic hysterectomies on women's sexuality and psychological condition. Turk J Obstetr Gynecol. 2016; 13(4): 196. [DOI:10.4274/tjod.71245].

16. Nam AN, Cho SH, Seo SK, Jeon YE, Kim HY, Choi YS, Lee BS. Laparoscopic total hysterectomy versus laparoscopic supracervical hysterectomy: the effect on female sexuality. J Womens Med. 2008; 1(1): 43-47. https://ir. ymlib. yonsei.ac.kr/handle/ 22282913/107331.

17. Radosa JC, Meyberg-Solomayer G, Kastl C, Radosa CG, Mavrova R, Gräber S, Radosa MP. Influences of different hysterectomy techniques on patients' postoperative sexual function and quality of life. J Sexual Med. 2014; 11(9): 2342-2350. [DOI: 10.1111/jsm. 12623].

18. Farrell SA, Kieser K. Sexuality after hysterectomy. Obstetr Gynecol. 2000; 95(6): 1045-1051. [DOI: 10.1016/ s0029-7844(00)00784-5].

19. Lone F. Evidence Based Review of Hysterectomy and Sexuality. In Hysterectomy. Springer, Cham. 2018; pp 133-138. [DOI: 10.1007/978-3-319-22497-8_9].

20. Wierrani F, Huber M, Grin W, Henry M, Grünberger W. Postoperative libido and genital sexual sensitivity following various forms of hysterectomy. J Gynecol Surg. 1995; 11(3):127-132. [DOl: 10.1089/gyn.1995.11.127]. 
21. Galyer KT, Conaglen HM, Hare A, Conaglen JV. (1999). The effect of gynecological surgery on sexual desire. J Sex Marital Ther. 1999; 25(2): 81-88. [DOI 10. 1080/00926239908403981].

22. Griffith-Jones MD, Jarvis GJ, McNamara HM. Adverse urinary symptoms after total abdominal hysterectomy-fact or fiction? Br J Urol 1991; 67(3): 295-297. [DOI: 10.1111/ j.1464-410x.1991.tb15138.x].

23. Lee JH, Choi JS, Hong JH, Joo, KJ, Kim BY. Does conventional or single port laparoscopically assisted vaginal hysterectomy affect female sexual function? Acta Obstetricia et Gynecologica Scandinavica 2011; 90(12): 1410-1415. [DOI: 10.1111/j.1600-0412.2011. 01255.x].

24. Rhodes JC, Kjerulff KH, Langenberg PW, Guzinski GM. Hysterectomy and sexual functioning. JAMA 1999; 282 (20): 1934-1941. [DOI: 10.1001/jama.282.20.1934].

25. Mokate T, Wright C, Mander T. (2006). Hysterectomy and sexual function. Br Menopause Soc J. 2006; 12(4): 153-157. [DOI: 10.1258/136218006779160607].

26. Kilkku P, Grönroos M, Hirvonen T, Rauramo L. Supra vaginal uterine amputation vs. hysterectomy: Effects on libido and orgasm. Acta obstetricia et gynecologica scandinavica 1983; 62(2), 147-152. [DOI: 10.3109/ $00016348309155779]$.
27. Kilkku P. Supravaginal uterine amputation VS. hysterectomy: Effects on coital frequency and dyspareunia. Acta Obstetricia et Gynecologica Scandinavica 1983; 62(2), 141-145. [DOI: 10.3109/00016348309155778].

28. Thakar R, Ayers S, Clarkson P, Stanton S, Manyonda I. Outcomes after total versus subtotal abdominal hysterectomy. NEJM 2002; 347(17): 1318-1325. [DOI: 10.1056/nejmoa013336].

29. Zobbe V, Gimbel H, Andersen BM, Filtenborg T, Jakobsen K, Sørensen HC, Vejtorp M. Sexuality after total vs. subtotal hysterectomy. Acta Obstetricia et Gynecologica Scandinavica 2004; 83(2): 191-196. [DOI: 10.1111/j.0001-6349.2004. 00311.x].

30. Thakar R, Ayers S, Georgakapolou A, Clarkson P, Stanton S, Manyonda I. Hysterectomy improves quality of life and decreases psychiatric symptoms: a prospective and randomized comparison of total versus subtotal hysterectomy. BJOG 2004; 111(10), 1115-1120. [DOI: 10.1111/j.1471-0528.2004. 00242.x].

31. Hartmann KE, Ma C, Lamvu GM, Langenberg PW, Steege JF, Kjerulff KH. Quality of life and sexual function after hysterectomy in women with preoperative pain and depression. Obstetrics \& Gynecology 2004; 104(4), 701709. [DOI: 10.1097/01.aog.0000140684.37428.48]. 